Under the auspices of the International Committee international journal of metrology, Metrologia, commenced quarterly publication by Springer in January 1965. The general oditor is Dr. L. E. Howlett (National Research Council, Ottawa), chairman of the International
Committee, who is assisted by an international editoria I board.

H. BARRELL

${ }^{2}$ Markowitz, W., Glenn Hall, R., Essen, L., and Parry, J. V. I., Phys. IRev. lett., 1, 105 (1958).

Barrell, H., Nature, 188, 195 (1961).

\title{
NON-CUTTING USES OF INDUSTRIAL DIAMONDS
}

$\mathrm{M}$ OST industrial diamonds are used for cutting purposes where the objective is removal or displacement of relatively hard materials such as metal or rock. There are, howover, other important applications of these diamonds which are not so well known, in particular 'non-cutting' uses. In this category are recognized mechanical and non-mechanical applications; the former include processes where the diamond is employed as an integral working part of a machine; the latter implies those instances where it is performing other independent functions. A recently issued publication entitled NonCutting Uses of Industrial Diamonds* briefly describes and illustrates some of the more important non-cutting applications of these diamonds.

In the category of mechanical uses are styli, what are known as 'feeler' styli, diamond distance stops, gramophone styli and bearings. All these uses depend on the factor of extreme hardness of diamond and the facility with which it can be shaped and polished to a very high degree of accuracy and tolerance for the particular purpose in view, with the assurance of retention of shape and high surface finish for a far longer time than any other material. Feeler styli are employed as sensitive feelers in a wide variety of surface measuring instruments; they are ground

* Industrial Diamond Information Bureau. Non-Cutting Uses of Industrial Diamonds. Pp. 12. (London: Industrial Diamond Information Bureau, 1964.) into cone shape and have an accurate radius polished on the tip; for example, high-resolution types of feeler styli have a tip radius of $0.00005 \mathrm{in}$. Diamond distance stops are used in distance pieces to ensure accuracy in lapping and honing operations in cases where the finished workpiece is to be of pre-determined thickness. With gramo. phone styli the diamonds are ground to cone shape and the tip polished to a radius varying according to the type of record to be produced or played; styli for microgrooveand stereo-records require far finer tips than those used to play the old standard 78-r.p.m. records.

As an example of their use as bearings, precision watchmaking may be cited, where in such fine mechanisms diamonds replace natural or synthetic ruby, especially in cases demanding accuracy, long life and frictionless bearings. In the category of non-mechanical applications there are optical uses, electronic functions, and diamondtipped indenters, such as are used on some hardness testing machines. In the optical field, the diamonds must be of gem quality, clear as optical glass. Electronic applications chiefly concern the use of semiconducting diamonds which have proved extremely efficient as sensitive detector heads in thermistor equipment; they can also be used as radiation counters; for this purpose only very small diamonds are used, and since they are chemically inert they make eminently suitable implant detectors in the living body, apparently without any harmful effects.

\section{ANGULAR SIZES OF THE X-RAY SOURCES IN SCORPIO AND SAGITTARIUS}

\author{
By M. ODA*, G. CLARK, G. GARMIRE and M. WADA $\dagger$ \\ Laboratory for Nuclear Science, Massachusetts Institute of Technology, Cambridge, Massachusetts \\ AND \\ Prof. R. GIACCONI, Dr. H. GURSKY and J. WATERS \\ American Science and Engineering Inc., Cambridge, Massachusetts
}

\begin{abstract}
$\mathrm{T}$ HE angular diameters of the X-ray source regions in the constellations Scorpio and Sagittarius respectively have been investigated in two rocket experiments conducted on August 28, 1964 (flight I), and October 24, 1964 (flight II), at the White Sands Missilo Range. These sources were first observed by Giacconi et al. ${ }^{1}$ as a single unresolved source of cosmic $\mathrm{X}$-rays with wave-lengths around $3 \AA$ and located near the galactic centre. Subsequent observations by Friedman et $a .^{2}{ }^{2}$ and by Giacconi et al. ${ }^{3}$ established the existence of two separate sources, in this part of the sky, one located near right ascension $16^{\mathrm{h}} 15^{\mathrm{m}}$, declination $-15^{\circ}$, and the other near or coincident with the radio centre of the galaxy. In the present experiments we observed these two sources with a detector using a special collimator which has a high angular resolving power and at the sarne time a large field of view.

Flight I was launched at a sidereal time of $20 \mathrm{~h} 56 \mathrm{~min}$, and flight II at a sidereal time of $20 \mathrm{~h} 20 \mathrm{~min}$. In both flights, the rocket motion consisted of a rapid spin about

* On Ieavo from the Institute for Nuclear Study, University of Tokyo.

$t$ On leave from the Institute of Physical and Chemical Research, Tokyo.
\end{abstract}

its long axis and a slow precession of the long axis around a yaw cone of small opening angle. The dotectors themselves were banks of Geiger-Miiller tubes with beryllium windows 0.002 in. thick. Each bank had a sensitive area of approximately $100 \mathrm{~cm}^{2}$. The collima. tors, which have been described elsewhere ${ }^{4}$, consist of two grids of parallel wires. Each wire is separated from the adjacent wires by slightly less than one wire diameter, and the two grids are mounted one in the back of the other and separated by a distance of 1.5 in. (as dictated by the available space in the instrument section of the rocket). Parallel radiation falling on the collimator casts a shadow of the wires forming the front grid on to the back grid. The transmission of the incident radiation passing through the back grid and into the detectors is determined by whether the shadow coincides with the back wires or with the openings between. As the apparatus is rotated around an axis parallel to the wires, the intensity transmitted by the collimator is modulated in a way that is determined by the dimensions of the wire grids and the rate of rotation. On the other 